\title{
Living alone and antidepressant medication use: a prospective study in a working-age population
}

\author{
Laura Pulkki-Råback ${ }^{1,2^{*}}$, Mika Kivimäki ${ }^{1,3}$, Kirsi Ahola ${ }^{1}$, Kaisla Joutsenniemi ${ }^{4}$, Marko Elovainio ${ }^{4}$, Helena Rossi ${ }^{1}$, \\ Sampsa Puttonen ${ }^{1,2}$, Seppo Koskinen ${ }^{4}$, Erkki Isometsä ${ }^{4,5}$, Jouko Lönnqvist ${ }^{4,5}$ and Marianna Virtanen ${ }^{1}$
}

\begin{abstract}
Background: An increasing proportion of the population lives in one-person households. The authors examined whether living alone predicts the use of antidepressant medication and whether socioeconomic, psychosocial, or behavioral factors explain this association.

Methods: The participants were a nationally representative sample of working-age Finns from the Health 2000 Study, totaling 1695 men and 1776 women with a mean age of 44.6 years. In the baseline survey in 2000, living arrangements (living alone vs. not) and potential explanatory factors, including psychosocial factors (social support, work climate, hostility), sociodemographic factors (occupational grade, education, income, unemployment, urbanicity, rental living, housing conditions), and health behaviors (smoking, alcohol use, physical activity, obesity), were measured. Antidepressant medication use was followed up from 2000 to 2008 through linkage to national prescription registers.
\end{abstract}

Results: Participants living alone had a 1.81-fold $(\mathrm{Cl}=1.46-2.23)$ higher purchase rate of antidepressants during the follow-up period than those who did not live alone. Adjustment for sociodemographic factors attenuated this association by $21 \%$ (adjusted $\mathrm{OR}=1.64, \mathrm{Cl}=1.32-2.05$ ). The corresponding attenuation was $12 \%$ after adjustment for psychosocial factors (adjusted $\mathrm{OR}=1.71, \mathrm{Cl}=1.38-2.11$ ) and $9 \%$ after adjustment for health behaviors (adjusted $\mathrm{OR}=1.74, \mathrm{Cl}=1.41-2.14)$. Gender-stratified analyses showed that in women the greatest attenuation was related to sociodemographic factors and in men to psychosocial factors.

Conclusions: These data suggest that people living alone may be at increased risk of developing mental health problems. The public health value is in recognizing that people who live alone are more likely to have material and psychosocial problems that may contribute to excess mental health problems in this population group.

Keywords: Mental health, Antidepressant medication, Living arrangement, Psychosocial factors, Socioeconomic

\section{Background}

The proportion of one-person households has doubled during the past three decades, with every third person in the U.S. and the U.K. living alone [1,2]. It has been estimated that by 2020 , nearly $40 \%$ of all households will have only one inhabitant [3]. At the same time, there has been a dramatic increase in the consumption of antidepressant medications $[4,5]$. The potentially catastrophic consequences of single living were evident during the 1995 heat wave in Chicago, when most of the deaths

\footnotetext{
* Correspondence: laura.pulkki-raback@helsinki.fi

${ }^{1}$ Finnish Institute of Occupational Health, Topeliuksenkatu 41 a A, 00250 Helsinki, Finland

Full list of author information is available at the end of the article
}

occurred among elderly people living alone [6]. However, the long-term consequences of single living are poorly understood, because never before in history has there been such a great proportion of people living alone.

Living alone has been associated with psychological disadvantages and an increased risk of mental health problems, higher rates of consumption of psychotropic drugs [7-12], and a higher risk of suicide [13] compared to living with other persons in the same household. A prospective study demonstrated that household structure, that is, the social composition of people who reside in the same household, was a more important determinant of well-being than marital status in middle-aged people [14]. However, most studies in this field of research have
C Biomed Central

(c) 2012 Pulkki-Råback et al; licensee BioMed Central Ltd. This is an Open Access article distributed under the terms of the Creative Commons Attribution License (http://creativecommons.org/licenses/by/2.0), which permits unrestricted use, distribution, and reproduction in any medium, provided the original work is properly cited. 
been cross-sectional and have concentrated on selected populations such as elderly people living alone $[15,16]$ or single parents [17]. Little is known about the mental health outcomes associated with single living in economically active people who represent the majority of the working-age population $[13,18]$.

Several possible reasons may explain why people living alone suffer from poorer mental health, and why people living with others generally have better mental health. Living with other persons may offer emotional support, feelings of social integration, as well as tangible factors that protect against mental health problems $[16,19,20]$. Living alone, in turn, may be associated with psychosocial deficits such as feelings of isolation [13,19-22] and a lack of social integration and trust, which, in turn, are risk factors for mental health [23-25]. Single people may also face distress due to socioeconomic disadvantages, such as financial difficulties, and they may be prone to adverse health behaviors $[19,21,22,26]$. In working-age people, single living may be associated with poorer well-being in working life which, in turn, is known to be a predictor of mental health problems $[24,27]$. We are aware of no previous study that has examined aspects of working life as potential contributors to the association between living arrangements and mental health outcomes.

In the present study, we used antidepressant medication as a proxy measure for the most common mental disorders [28], as antidepressants are indicated for both depression and anxiety-related conditions. Our aim was two-fold: to examine 1) whether living alone was associated with antidepressant use during a 7-year period, and 2) the extent to which psychosocial, socioeconomic, and behavioral factors explained any observed association between living alone and the use of antidepressant medication. This study was based on data from Finnish working-age (30 to 65 years) men and women who formed a representative sample of the Finnish working population.

\section{Methods}

\section{Participants}

The participants were men and women from the Health 2000 Study [29], which was a two-stage stratified cluster sample representative of the Finnish mainland population aged 30 years or over. The base sample comprised 5871 participants between 30 and 65 years of age. We included those who were currently working or who had been working during the previous 12 months, thus reflecting current or recent economic activity. The sample with complete information on all study variables consisted of 3471 participants. Previously, it has been shown that the drop-outs had more depressive symptoms, were more often male, lived alone, and were more often economically inactive than those who participated $[11,30]$. The respondents received an information leaflet and gave their written informed consent. The Health 2000 Study was approved by the Ethics Committee for Epidemiology and Public Health in the Hospital District of Helsinki and Uusimaa in Finland, and the study was performed in accordance with the ethical standards of the Declaration of Helsinki.

\section{Measures}

Living arrangements were examined at the baseline examination between August 15, 2000 and February 28, 2001. The participants were asked: "How many persons live in your household, including you?" The participants were classified as "living alone" if they reported a household size of one person, and "not living alone" if they reported a household size of two or more persons. The validity of this question was examined by cross-tabulating living arrangements with self-reported marital status. Of the 504 persons living alone, 184 were divorced, 25 widows, and 295 lived alone without a specific reason. There were 13 married persons living alone; we decided to retain them among the 504 persons who were classified as living alone, as they might have been separated but not yet divorced.

Information on antidepressant medications purchased at pharmacies between January 1, 2000 and December 31, 2008 was obtained from the National Prescription Register managed by the Social Insurance Institution of Finland. This register covers the entire outpatient population and all reimbursed doctor-prescribed medications in Finland. Participants who had purchased at least one prescription coded as N06A (the WHO Anatomical Therapeutic Chemical classification code for antidepressants) were considered as antidepressant users. Three variables were formed: baseline users (who had purchased at the study baseline between 2000 and 2001), users at follow-up (who had purchased between 2002 and 2008), and incident users (who had purchased between 2002 and 2008, but not at baseline).

Psychosocial factors included self-reports of a poor job climate (4-item questionnaire) [31], a lack of support at the workplace (2-item scale) [32], a lack of social support in private life (4-item scale) [33], and cynical hostility (8item scale) [34]. Participants not currently working were asked to report the working conditions during the previous 12 months. For all psychosocial factors, the highest tertile represented those rated high in the characteristic. There were two main reasons for using categorical variables instead of continuous ones: (1) it enabled a better comparison with previous studies using similar measures $[27,35]$, and (2) the assumption underlying the use of continuous variables is that each increment in the distribution equally adds risk, but this is not necessarily the case, as threshold effects are possible in a study where the outcome is a dichotomous mental health variable. 
Sociodemographic factors were a low occupational grade (manual-level employee versus non-manual), a lack of educational qualifications (lack of secondary-level education versus having a degree), a low household income (as defined by the OECD: income per consumption unit below $50 \%$ of the national median), currently being outside work life (unemployed/home-maker/student/retired versus currently having a job), urban residency (living in a city or it's outskirts versus rural living), rental living (renting versus owning one's accommodation), and poor housing conditions (having $\geq 2$ housing disadvantages including noise, draft, dirt, damp, chilliness, and fear versus having $<2$ disadvantages).

Health risk behaviors included daily smoking (non-smokers versus smokers), heavy alcohol use (moderate users versus heavy users: $>20 \mathrm{~g} /$ day for women, $>40 \mathrm{~g} /$ day for men), low physical activity (any activity, including walking, $\geq 4$ per week representing "high activity" versus $<4$ times per week representing "low activity"), and obesity (body mass index $<30$ versus $\geq 30$ ).

\section{Data analysis}

The data were analyzed using SAS 9.1 survey procedures and SUDAAN 9 software. This software applies weighting adjustments and sampling parameters to account for the clustering of a stratified sample. We used logistic regression analysis to examine the association of the living arrangement (alone vs. not alone) with the odds for having purchased reimbursed prescriptions of antidepressant medication. These analyses examined a) the cross-sectional use of antidepressants (baseline purchases of antidepressants as the outcome), b) the longitudinal use of antidepressants (purchases of antidepressant medication at any time during the 7-year follow-up period), and c) incident use of antidepressants (starting to use antidepressants during the 7-year follow-up period). We entered socioeconomic factors, psychosocial factors, and health behaviors as separate blocks in the age- and gender-adjusted models, and we calculated the percentage change in the odds ratio (OR) to evaluate their influence on the association between living arrangements and antidepressant use. These analyses were conducted in all participants, and additionally stratified by gender.

\section{Results}

Characteristics of the study variables according to gender are presented in Table 1. Of the 3471 participants, 14.5\% reported living alone, with an equal proportion of men and women living alone. The prevalence of antidepressant use in all participants was $6.2 \%$ at baseline, and altogether $17.2 \%$ used antidepressants at some point during the 7 -year follow-up period. Each year, $1 \%$ to $2 \%$ of participants started to use antidepressants, and the prevalence of incident use during the entire follow-up period was $12.9 \%$ (year-by-year figures are provided in Additional file 1: Annex Table 1). Women had a greater prevalence and incidence of antidepressant use than men. Compared to women, men had less social support at work and a lower occupational grade than women, more often lived in rural areas, smoked more often, and used alcohol more heavily than women.

Table 2 presents psychosocial, demographic, and behavioral factors according to living arrangements. Participants living alone experienced a worse job climate, less support in private life, had a higher level of cynical hostility, were more often non-employed, lived in urban areas, were more likely to live in rental accommodation, had worse housing conditions, were more often smokers and used alcohol more heavily than those who did not live alone.

When comparing purchases of antidepressants, those living alone had purchased antidepressants more often than those who did not live alone (9.1\% versus $5.7 \%$ ) at the baseline examination. Likewise, during the follow-up period, $25.4 \%$ of persons living alone versus $15.8 \%$ of others had purchased antidepressants in any year between 2002 and 2008. As shown in Table 3 living alone was associated with a 1.61 -fold higher $(\mathrm{CI}=1.12-2.25)$ purchase rate of antidepressants at baseline and 1.81-fold higher $(C I=1.46-2.23)$ rate during the 7 following years compared with people who did not live alone. When the analyses were restricted to participants who started antidepressant use after the baseline examination (incident use), the association remained similar $(\mathrm{OR}=1.71, \mathrm{CI}=$ 1.32-2.21).

Sociodemographic factors attenuated these associations by $18 \%, 21 \%$, and $20 \%$. As shown in Table 3 the ORs adjusted for sociodemographic factors were $1.48(\mathrm{CI}=$ 1.04-2.09) for baseline antidepressant use, 1.64 (CI = 1.32-2.05) for 7-year use, and $1.57(\mathrm{CI}=1.21-2.05)$ for incident antidepressant use. Psychosocial factors attenuated the associations by $30 \%, 12 \%$, and $6 \%$, with the adjusted ORs being $1.43(\mathrm{CI}=1.03-1.99)$ for baseline use, $1.71(\mathrm{CI}=1.38-2.11)$ for 7 -year use, and $1.67(\mathrm{CI}=1.29$ 2.16) for incident antidepressant use. Finally, health behaviors had only a marginal effect on the associations between living arrangements and antidepressant use, with adjusted ORs of $1.58(\mathrm{CI}=1.25-2.21), 1.74(\mathrm{CI}=$ 1.41-2.14), and 1.64 ( $\mathrm{CI}=1.26-2.12)$, corresponding to a contribution of $5 \%$ to $9 \%$ owing mainly to heavy alcohol use.

There was no statistical evidence to suggest that gender modifies the association between living arrangements and antidepressant use $(P$-values for gender $\times$ living arrangement interactions were $0.618,0.673$, and 0.984 ). However, the underlying mechanisms could be gender-specific. Thus, we ran the analyses shown for the total cohort in Table 3 stratified by gender to examine 


\begin{tabular}{|c|c|c|c|c|}
\hline & \multicolumn{4}{|l|}{ n (\%) } \\
\hline & $\begin{array}{c}\text { Men } \\
(n=1695)\end{array}$ & $\begin{array}{c}\text { Women } \\
(n=1776)\end{array}$ & $\begin{array}{c}\text { All } \\
(n=3471)\end{array}$ & $\begin{array}{c}P \text { for gender } \\
\text { difference }\end{array}$ \\
\hline Number of participants living alone & $244(14.4)$ & $260(14.6)$ & $504(14.5)$ & 0.838 \\
\hline \multicolumn{5}{|l|}{ Number of antidepressant users: } \\
\hline At baseline & $75(4.4)$ & $140(7.9)$ & $215(6.2)$ & $<0.001$ \\
\hline During 7-year follow-up & $235(13.9)$ & $362(20.4)$ & $597(17.2)$ & $<0.001$ \\
\hline Incident users during 7-year follow-up & $175(10.3)$ & $245(13.8)$ & $420(12.1)$ & 0.002 \\
\hline \multicolumn{5}{|l|}{ Psychosocial factors: ${ }^{a}$} \\
\hline Poor job climate & $622(36.7)$ & $604(34.0)$ & $1226(35.3)$ & 0.098 \\
\hline Lack of support at the workplace & $618(36.5)$ & $551(31.0)$ & $1169(33.7)$ & 0.001 \\
\hline Lack of social support in private life & $600(35.4)$ & $626(35.2)$ & $1226(35.3)$ & 0.926 \\
\hline High cynical hostility & $455(26.8)$ & $466(26.2)$ & $921(26.5)$ & 0.687 \\
\hline \multicolumn{5}{|l|}{ Sociodemographic factors: } \\
\hline Low occupational grade (blue-collar) & $753(44.4)$ & $431(24.3)$ & $1184(34.1)$ & $<0.001$ \\
\hline Lack of secondary education & $387(22.8)$ & $384(21.6)$ & $771(22.2)$ & 0.391 \\
\hline Low income ( $<50 \%$ of national median) & $182(10.7)$ & $213(12.0)$ & $395(11.4)$ & 0.244 \\
\hline Temporarily outside working life ${ }^{b}$ & $122(7.2)$ & $170(9.6)$ & $292(8.4)$ & 0.012 \\
\hline Urban residency & $1058(62.4)$ & $1193(67.2)$ & $2251(64.9)$ & 0.003 \\
\hline Living at rent & $379(22.4)$ & $402(22.6)$ & $781(22.5)$ & 0.846 \\
\hline Poor housing conditions ${ }^{c}$ & $152(9.0)$ & $185(10.4)$ & $337(9.7)$ & 0.149 \\
\hline \multicolumn{5}{|l|}{ Health behaviors: } \\
\hline Daily smokers & $490(28.9)$ & $380(21.4)$ & $870(25.1)$ & $<0.001$ \\
\hline Heavy alcohol use ${ }^{d}$ & $241(14.2)$ & $135(7.6)$ & $376(10.8)$ & $<0.001$ \\
\hline Infrequent physical activity ${ }^{e}$ & $336(19.8)$ & $424(23.9)$ & $760(21.9)$ & 0.004 \\
\hline Obesity (BMI $\geq 30$ ) & $310(18.3)$ & $340(19.1)$ & $650(18.7)$ & 0.519 \\
\hline
\end{tabular}

The Health 2000 Study, $n=3471$

${ }^{\text {a }}$ The highest tertile is the cut-off point

b Unemployed, home-maker, full-time student, or retired during past 12 months

'At least 2 of the following: draft, noise, dust or dirt, dampness, chilliness, crowding, fear

${ }^{\mathrm{d}}$ According to WHO definintion: $>20 \mathrm{~g}$ for women per day, $>40 \mathrm{~g}$ for men per day

éess than 4 times per week of any activity, including moderate activity such as walking

whether the contributing factors differed between men and women. Table 4 shows that in men, psychosocial factors had the greatest contributing effect on the association between living arrangements and antidepressant use (attenuations were 31\%, 21\%, and 15\%). In women, sociodemographic factors stood out as the major contributors, showing attenuations of $24 \%, 27 \%$, and $31 \%$.

Finally, we conducted a sensitivity analysis to examine whether the associations were dependent of the length of the follow-up period. We repeated the analysis of living arrangements and antidepressant use for a 2-year instead of a 7-year follow-up period. The association was directionally similar but slightly weaker than in the main analysis (Additional file 2: Annex Table 2). The contributing factors were similar in magnitude to those in the main analysis, with sociodemographic factors having the greatest contribution and health behaviors the lowest contribution to the greater antidepressant use of participants living alone.

\section{Discussion}

This study suggested that living alone is associated with the prospective use of antidepressant medication in a nationally representative Finnish working-age sample. Those who lived alone had an $80 \%$ higher risk of initiating antidepressant use during the 7-year follow-up compared with participants who did not live alone. Socioeconomic adversity explained part of this relationship, especially in women. Psychosocial factors, including a lack of social support, were important explanatory factors in men. Health behaviors had only a marginal contribution to the association between living alone and antidepressant use among men and women, with the exception of heavy alcohol use in men. This is in agreement with a previous register-based study showing a strong link between living alone and alcohol-related mortality [36]. All the factors included in this study explained $46 \%$ of the associations, thus leaving the majority of the association between living alone and antidepressant use unexplained. 
Table 2 Comparison of psychosocial, socioedmographic and behavioral factors in participants not living alone versus those living alone

\begin{tabular}{|c|c|c|c|c|}
\hline \multirow[b]{2}{*}{ Characteristic } & \multicolumn{4}{|l|}{ n (\%) } \\
\hline & $\begin{array}{l}\text { Not living alone } \\
\quad(\mathrm{n}=2967)\end{array}$ & $\begin{array}{l}\text { Living alone } \\
\qquad(\mathrm{n}=504)\end{array}$ & $\begin{array}{c}\text { All } \\
(n=3471)\end{array}$ & $\begin{array}{l}P \text { for alone } \\
\text { vs. not alone }\end{array}$ \\
\hline \multicolumn{5}{|l|}{ Psychosocial factors: $^{a}$} \\
\hline Poor job climate & $1016(34.3)$ & $210(42.0)$ & $1226(35.3)$ & 0.002 \\
\hline Lack of support at the workplace & $999(33.8)$ & $170(34.0)$ & $1169(33.7)$ & 0.923 \\
\hline Lack of social support in private life & $984(33.3)$ & $242(48.2)$ & $1226(35.3)$ & $<0.001$ \\
\hline High cynical hostility & $760(25.8)$ & $161(32.3)$ & $921(26.5)$ & 0.004 \\
\hline \multicolumn{5}{|l|}{ Sociodemographic factors: } \\
\hline Low occupational grade (blue-collar) & $996(34.1)$ & $188(38.1)$ & $1184(34.1)$ & 0.089 \\
\hline Lack of secondary education & $648(22.2)$ & $123(24.7)$ & $771(22.2)$ & 0.238 \\
\hline Low income ( $<50 \%$ of national median) & $338(11.2)$ & $57(11.3)$ & $395(11.4)$ & 0.940 \\
\hline Temporarily outside working life $\mathrm{e}^{\mathrm{b}}$ & $238(7.8)$ & $54(10.5)$ & $292(8.4)$ & 0.060 \\
\hline Urban residency & $1873(63.3)$ & $378(74.8)$ & $2251(64.9)$ & $<0.001$ \\
\hline Living at rent & $560(18.7)$ & $221(43.4)$ & $781(22.5)$ & $<0.001$ \\
\hline Poor housing conditions ${ }^{c}$ & $272(9.1)$ & $65(12.7)$ & $337(9.7)$ & 0.029 \\
\hline \multicolumn{5}{|l|}{ Health behaviors: } \\
\hline Daily smokers & $716(24.3)$ & $154(30.7)$ & $870(25.1)$ & 0.002 \\
\hline Heavy alcohol use ${ }^{d}$ & $302(10.4)$ & $74(15.0)$ & $376(10.8)$ & 0.005 \\
\hline Infrequent physical activity ${ }^{\mathrm{e}}$ & $635(21.3)$ & $125(24.6)$ & $760(21.9)$ & 0.107 \\
\hline Obesity (BMI $\geq 30$ ) & $554(18.9)$ & $96(18.9)$ & $650(18.7)$ & 0.990 \\
\hline
\end{tabular}

The Health 2000 Study, $n=3471$

${ }^{\text {a }}$ The highest tertile is the cut-off point

${ }^{\mathrm{b}}$ Unemployed, home-maker, full-time student, or retired during past 12 months

'At least 2 of the following: draft, noise, dust or dirt, dampness, chilliness, crowding, fear

${ }^{\mathrm{d}}$ According to WHO definintion: $>20 \mathrm{~g}$ for women per day, $>40 \mathrm{~g}$ for men per day

e Less than 4 times per week of any activity, including moderate activity such as walking

Our findings are in line with previous reports suggesting that single people suffer from ill health due to material and socioeconomic disadvantages [19,21]. In our study, urban living, poor housing conditions, and rental living contributed to the association between living alone and antidepressant use. Their effect was more pronounced in women than men. A systematic review demonstrated that the very same environmental factors - housing quality, housing tenure, and urban living - had the strongest mental health effects [37]. The direction of causality in our study may go either way: poor living conditions may cause depression, but they may also be a consequence of earlier mental health problems.

Table 3 Odds ratios (OR) for use of antidepressants in participants living alone compared to participants not living alone

\begin{tabular}{|c|c|c|c|c|c|c|}
\hline \multirow[b]{3}{*}{ Predictor: living alone (ref. = not alone) } & \multicolumn{6}{|c|}{ Use of antidepressant medication } \\
\hline & \multicolumn{2}{|c|}{ At baseline } & \multicolumn{2}{|c|}{ During 7-year follow-up } & \multicolumn{2}{|c|}{ Incident 7-year use ${ }^{a}$} \\
\hline & OR $(95 \% \mathrm{Cl})$ & $\%$ reduction & OR $(95 \% \mathrm{Cl})$ & $\%$ reduction & OR $(95 \% \mathrm{Cl})$ & $\%$ reduction \\
\hline \multicolumn{7}{|l|}{ Adjustment in addition to age and gender: } \\
\hline 1. None & $1.61(1.15-2.25)$ & 0 & $1.81(1.46-2.23)$ & 0 & $1.71(1.32-2.21)$ & 0 \\
\hline 2. Psychosocial factors ${ }^{b}$ & $1.43(1.03-1.99)$ & 30 & $1.71(1.38-2.11)$ & 12 & $1.67(1.29-2.16)$ & 6 \\
\hline 3. Sociodemographic factors ${ }^{c}$ & $1.48(1.04-2.09)$ & 18 & $1.64(1.32-2.05)$ & 21 & $1.57(1.21-2.05)$ & 20 \\
\hline 4. Health behaviors ${ }^{d}$ & $1.58(1.25-2.21)$ & 5 & $1.74(1.41-2.14)$ & 9 & $1.64(1.26-2.12)$ & 10 \\
\hline 5. All of the above & $1.33(0.93-1.89)$ & 46 & $1.55(1.23-1.94)$ & 32 & $1.53(1.16-2.00)$ & 25 \\
\hline
\end{tabular}

Data: The Health 2000 Study, $\mathrm{n}=3471$

${ }^{a}$ New users during the follow-up with no purchases at the baseline (in 2000 or 2001)

b Low social support at the workplace, low social support in private life, poor job climate, hostile personality

'Low educational level, low occupational grade, low income, unemployement, urbanicity, living at rent, housing disadvantages

${ }^{\mathrm{d}}$ Regular smoking, alcohol heavy use (> $20 \mathrm{~g}$ women, $>40 \mathrm{~g}$ men), sedentary lifestyle, obesity (BMI > 30) 
Table 4 Odds ratios (OR) for use of antidepressants in participants living alone compared to participants not living alone, separately for men and women

\begin{tabular}{|c|c|c|c|c|c|c|}
\hline \multirow[b]{3}{*}{ Predictor: living alone (ref. = not alone) } & \multicolumn{6}{|c|}{ Use of antidepressant medication } \\
\hline & \multicolumn{2}{|l|}{ At baseline } & \multicolumn{2}{|c|}{ During 7-year follow-up } & \multicolumn{2}{|c|}{ Incident 7-year use ${ }^{a}$} \\
\hline & OR $(95 \% \mathrm{Cl})$ & $\%$ reduction & OR $(95 \% \mathrm{Cl})$ & $\%$ reduction & OR $(95 \% \mathrm{Cl})$ & $\%$ reduction \\
\hline & \multicolumn{6}{|c|}{ Men $(n=1695)$} \\
\hline \multicolumn{7}{|l|}{ Adjustment in addition to age and gender: } \\
\hline 1. None & $1.85(1.06-3.25)$ & 0 & $1.72(1.21-2.44)$ & 0 & $1.62(1.09-2.41)$ & 0 \\
\hline 2. Psychosocial factors ${ }^{b}$ & $1.59(0.89-2.83)$ & 31 & $1.57(1.09-2.25)$ & 21 & $1.53(1.02-2.29)$ & 15 \\
\hline 3. Sociodemographic factors ${ }^{c}$ & $1.73(0.96-3.09)$ & 14 & $1.65(1.15-2.37)$ & 10 & $1.62(1.08-2.43)$ & 0 \\
\hline 4. Health behaviors ${ }^{\mathrm{d}}$ & $1.81(1.03-3.18)$ & 5 & $1.64(1.15-2.34)$ & 11 & $1.56(1.04-2.33)$ & 10 \\
\hline \multirow[t]{2}{*}{ 5. All of the above } & $1.56(0.86-2.85)$ & 34 & $1.51(1.04-2.20)$ & 29 & $1.52(1.00-2.31)$ & 16 \\
\hline & \multicolumn{6}{|c|}{ Women $(n=1776)$} \\
\hline \multicolumn{7}{|l|}{ Adjustment in addition to age and gender: } \\
\hline 1. None & $1.54(1.00-2-39)$ & 0 & $1.89(1.40-2.54)$ & 0 & $1.74(1.24-2.45)$ & 0 \\
\hline 2. Psychosocial factors ${ }^{\mathrm{b}}$ & $1.43(0.91-2.22)$ & 20 & $1.81(1.34-2.45)$ & 9 & $1.71(1.21-2.42)$ & 4 \\
\hline 3. Sociodemographic factors ${ }^{c}$ & $1.41(0.89-2.22)$ & 24 & $1.65(1.21-2.25)$ & 27 & $1.51(1.05-2.15)$ & 31 \\
\hline 4. Health behaviors ${ }^{d}$ & $1.50(0.97-2.32)$ & 7 & $1.83(1.36-2.46)$ & 7 & $1.70(1.20-2.39)$ & 5 \\
\hline 5. All of the above & $1.29(0.80-2.06)$ & 46 & $1.58(1.15-2.17)$ & 35 & $1.49(1.03-2.14)$ & 34 \\
\hline
\end{tabular}

Data: The Health 2000 Study, $\mathrm{n}=3471$

${ }^{a}$ New users during the follow-up with no purchases at the baseline (in 2000 or 2001)

${ }^{b}$ Low social support at the workplace, low social support in private life, poor job climate, hostile personality

'Low educational level, low occupational grade, low income, unemployement, urbanicity, living at rent, housing disadvantages

${ }^{\mathrm{d}}$ Regular smoking, alcohol heavy use (> $20 \mathrm{~g}$ women, > $40 \mathrm{~g}$ men), sedentary lifestyle, obesity (BMI > 30)

A lack of social support, a poor job climate, and a hostile personality were among the psychosocial factors that were associated with living alone and antidepressant use. A lack of supportive social contacts at work and in private life explained part of the association between living alone and antidepressant use in men. Previously, social problems at work and in private life have been associated with antidepressant consumption $[24,27]$. The concept of "social capital" may offer a theoretical framework for interpreting these findings. Living alone may be associated with less social capital [13,19-22], which, in turn, is a risk for mental health [23-25]. As hostility is a rather enduring personality characteristic associated with irritability, lack of trust, and negative social interactions [38], reverse causation may also play a role. Hostile personalities may be more likely to end up being without a partner due to unwillingness or a lack of skills to form warm and close social relations.

Our data were limited firstly due to the systematic drop-out, causing healthier and economically better-off individuals to be slightly over-represented. This may have restricted the variance in both the predictor variable (living arrangement) and in the outcome variable (antidepressant use), thus underestimating their effects. Second, we were unable to examine whether changes in living arrangements had an effect on antidepressant use. As we had no data on living status on follow-up, some misclassification was possible due to changes in living status after baseline, that is, someone who was originally living alone may have been co-habiting at the time of purchase of antidepressants. Although the main findings were replicated in sensitivity analyses over a shorter time-span, when a change in living status was less likely, this question remains to be examined in further studies. Moreover, we had no data on antidepressant use before the baseline measurement, and thus were unable to examine reverse causation, that is, whether people with prior depression are likely to drift into living alone. Although we showed that living arrangements were associated with starting to use antidepressants (incident use), inferences on whether living alone causes mental health problems are not possible based on this observational data set. Third, different reasons for living alone may be differently related to mental health, but we were unable to compare individuals who unwillingly lived alone with those living alone through choice. Neither were we able to measure the effect of different household compositions on mental health, such as the presence of children, a spouse, or elderly relatives. A large prospective study has shown that under certain circumstances, living with other people may be more stressful than living alone [14]. Future studies should examine the possible benefits of living alone, and the advantages and disadvantages of having other persons with different statuses in the household.

Furthermore, antidepressant use as the outcome variable may reflect help-seeking behavior or differences in access to health care. People using antidepressants have depression that has been diagnosed by a health care 
professional, and people with undiagnosed depression were not therefore identified. Moreover, people typically seek help if the disease is severe enough to cause functional disability [39], suggesting that participants with mild depressive symptoms may have been undetected. This may have resulted in underestimation of the number of depressed people and underestimation of the effects. Finally, some antidepressants, particularly tricyclic medication, are commonly used for non-psychiatric indications such as pain or sleeping problems $[12,40]$. However, it is unlikely that the indication of antidepressant use varies according to living arrangements [12].

The strengths of this study were that common rater variance was excluded because the sources of information on the outcome (national register-based data) and contributing factors (self-reported data) were independent of each other. Because all purchases of antidepressants are recorded in the national registers in Finland, we were able to track $100 \%$ of participants who had purchased antidepressant medication at least once during the study years (excluding medications used during hospitalization). We included a rather extensive set of well-established risk factors for mental health problems. To our knowledge, this is the first study to examine both private life and work life factors as contributors to the association between living arrangements and mental health outcomes within the same sample.

\section{Conclusion}

This study focused on a working-age population and its antidepressant use over almost a decade. Persons living alone faced several types of psychosocial and material disadvantage. We found evidence to suggest that the explanatory factors may be gender specific, with a lack of social support playing a greater role in men and socioeconomic disadvantages in women. These finding suggest that improving the quality of social relations and material circumstances should be important targets in mental health promotion. Further research is needed, as over half of the association between living alone and antidepressant use remained unexplained by the variables included in this study. Further insights may arise, for example, from assessments that cover social capital (that is, feelings of alienation and a lack of trust in society), critical life events and their accumulation over time, and childhood circumstances giving rise to psychological vulnerabilities in adulthood.

\section{Additional material}

Additional file 1: Prevalence and incidence of antidepressant use according to follow-up year. The Health 2000 Study, $n=3471$.
Additional file 2: Odds ratios (OR) for use of antidepressants during a 2-year follow-up period in participants living alone compared to participants not living alone. Data: The Health 2000 Study, $n=3471$.

\section{Acknowledgements}

This study was supported by the Academy of Finland (projects No 123621 [L. P.-R.], 124322 [M.K.] and 128002 [M.E.), and the University of Helsinki Research Funds (L. P.-R.). M. K. is supported by the Work Environment Foundation (WEF), Finland, and the BUPA Foundation, UK. M. E. is also supported by the WEF. None of the funding sources had any role in study design, in the collection, analysis and interpretation of data; in the writing of the report; and in the decision to submit the paper for publication.

\section{Author details}

${ }^{1}$ Finnish Institute of Occupational Health, Topeliuksenkatu 41 a A, 00250 Helsinki, Finland. ' $U n i t$ of Personality, Work and Health Psychology, Institute of Behavioral Sciences, University of Helsinki, P.O. Box 9, 00014 Helsinki, Finland. ${ }^{3}$ Department of Epidemiology and Public Health, University College London, 1-9 Torrington Place, WC1E 6BT London, UK. ${ }^{4}$ National Institute for Health and Welfare, P.O. Box 30, 00271 Helsinki, Finland. ${ }^{5}$ Department of Psychiatry and Helsinki University Central Hospital, University of Helsinki, P.O. Box 20, 00014 Helsinki, Finland.

\section{Authors' contributions}

L P-R was the principal investigator, conducted the data analyses, wrote the first draft, and will act as guarantor for the paper. MK, KA, KJ, ME, HR, SP, SK, $J$ and MV substantially contributed to conception and design of the study, interpretation of data, drafting the article critically for important intellectual content, and approved of the final version. All authors read and approved the final manuscript.

\section{Competing interests}

The authors declare that they have no competing interests.

Received: 23 June 2011 Accepted: 23 March 2012

Published: 23 March 2012

\section{References}

1. Kreider RM, Elliott DB: America's families and living arrangements: 2007. Current Population Reports P20-561 Washington, DC.: U.S. Census Bureau; 2009.

2. Ali R, Bugler C, Curtis D, Dunstan S, Lloyd K, Maurice S, Pobjoy A, Shemwell L, White J: General lifestyle survey 2008. Office for National Statistics 2008 [http://www.statistics.gov.uk], Cited October 2010.

3. Turner A: Living alone. It seems the UK is a nation of loners. The Times Online Volume Sept 22007.

4. Olfson M, Marcus SC: National patterns in antidepressant medication treatment. Arch Gen Psychiatry 2009, 66(8):848-856.

5. Laukkala $\mathrm{T}$, Isometsä E, Hämäläinen J, Heikkinen $\mathrm{M}$, Lindeman $\mathrm{S}, \mathrm{Aro} \mathrm{H}$ : Antidepressant treatment of depression in the Finnish General Population. Am J Psychiatry 2001, 158(12):2077-2079.

6. Klinenberg E: Dying alone:the social production of urban isolation. Ethnography 2001, 2:501-531.

7. Colman I, Croudace TJ, Wadsworth MEJ, Jones PB: Factors associated with antidepressant, anxiolytic and hypnotic use over 17 years in a national cohort. J Affect Disord 2008, 110(3):234-240.

8. Kessler RC, Chiu WT, Demler O, Walters EE: Prevalence, severity, and comorbidity of 12-month DSM-IV disorders in the National Comorbidity Survey Replication. Arch Gen Psychiatry 2005, 62:617-627.

9. Ohayon MM, Caulet M, Priest RG, Guilleminault C: Psychotropic medication consumption patterns in the UK general population. J Clin Epidemiol 1998, 51(3):273-283.

10. Scott KM, Wells JE, Angermeyer M, Brugha TS, Bromet E, Demyttenaere K, Girolamo G, Gureje O, Haro JM, Jin R, Karam AN, Kovess V, Lara C, Levinson D, Ormel J, Posada-Villa J, Sampson N, Takeshima T, Zhang M, Kessler R: Gender and the relationship between marital status and first onset of mood, anxiety and substance use disorders. Psychol Med 2010, 40:1495-505. 
11. Pirkola SP, Isometsä E, Suvisaari J, Aro H, Joukamaa M, Poikolainen K, Koskinen S, Aromaa A, Lönnqvist J: DSM-IV mood-, anxiety- and alcohol use disorders and their comorbidity in the Finnish general population. Results from the Health 2000 Study. Soc Psychiatry Psychiatr Epidemiol 2005, 40:1-10.

12. Sihvo S, Isometsä E, Kiviruusu O, Hämäläinen J, Suvisaari J, Perälä J, Pirkola S, Saarni S, Lönnqvist J: Antidepressant utilisation patterns and determinants of short-term and non-psychiatric use in the Finnish general adult population. J Affect Disord 2008, 110(1-2):94-105.

13. Haw C, Hawton K: Living alone and delibarate self-harm: a case-control study of characteristics and risk factors. Soc Psychiatr Psychiatr Epidemiol 2010, doi:10.1007/s00127-010-0278-z.

14. Hughes ME, Waite LJ: Health in houshold context: living arrangements and health in late middle age. J Health Soc Behav 2002, 43:1-21.

15. Fratiglioni $L$, Wang $H$, Ericsson K, Maytan M, Winblad B: Influence of social network on occurence of dementia: a community-based longitudinal study. Lancet 2000, 355(9212):1315-1319.

16. Håkansson K, Rovio S, Helkala E-L, Vilska A-R, Winblad B, Soininen H, Nissinen A, Mohammed AH, Kivipelto M: Association between mid-life marital status and cognitive function in later life: population based cohort study. BMJ 2009, 339(7712):b2462-b2469.

17. Afifi TO, Cox BJ, Enns MW: Mental health profiles among married, nevermarried, and separated/divorced mothers in a nationally representative sample. Soc Psychiatr Psychiatr Epidemiol 2006, 41(2):122-129.

18. Holt-Lunstad J, Smith TB, Layton JB: Social relationships and mortality risk: a meta-analytic review. PLOS Med 2010, 7(7):e1000316.

19. Waldron I, Hughes ME, Brooks TL: Marriage protection and marriage selection - prospective evidence for reciprocal effects of marital status and health. Soc Sci Med 1996, 43(1):113-123.

20. Holt-Lunstad J, Birmingham BS, Jones BQ: Is there something unique about marriage? The relative impact of marital status, relationship quality, and network social support on ambulatory blood pressure and mental health. Ann Behav Med 2008, 35:239-244

21. Lindström M: Marital status, social capital, material conditions and selfrated health: A population-based study. Health Policy 2009, 93(23):172-179.

22. Joutsenniemi K, Martelin T, Koskinen S, Martikainen PT, Härkänen TT, Luoto RM, Aromaa AJ: Official marital status, cohabiting, and self-rated health - time trends in Finland 1978-2001. Eur J Public Health 2006, 16(5):476-483

23. Fujiwara T, Kawachi I: A prospective study of individual-level social capital and major depression in the United States. J Epidemiol Community Health 2008, 62:627-633.

24. Kouvonen A, Oksanen T, Vahtera J, Stafford M, Wilkinson R, Schneider J, Väänänen $A$, Virtanen $M, C o x S J$, Pentti J, et al: Low workplace social capital as a predictor of depression. The Finnish Public Sector Study. Am J Epidemiol 2008, 167(10):1143-1151.

25. LIndström M: Invited commentary: Social capital, social contexts, and depression. Am J Epidemiol 2008, 167:1152-1154.

26. Joutsenniemi K, Martelin T, Martikainen P, Pirkola S, Koskinen S: Living arrangements and mental health in Finland. J Epidemiol Community Health 2005, 60(6):468-475.

27. Sinokki M, Hinkka K, Ahola K, Koskinen S, Kivimäki M, Honkonen T, Puukka P, Klaukka T, Lönnqvist J, Virtanen M: The association of social support at work and in private life with mental health and antidepressant use: The Health 2000 Study. J Affect Disord 2009, 115:36-45.

28. Eaton WW, Martins SS, Nestadt G, Bienvenu J, Clarke D, Alexandre P: The burden of mental disorders. Epidemiol Rev 2008, 30:1-14

29. Aromaa A, Koskinen S: Health and functional capacity in Finland. Baseline results of the Health 2000 Health Examination Survey (in Finnish). Publications of the National Public Health Institute Helsinki: National Public Health Institute; 2004.

30. Honkonen $\mathrm{T}$, Virtanen $\mathrm{M}$, Ahola K, Kivimäki M, Pirkola S, Isometsä $\mathrm{E}$, Aromaa A, Lönnqvist J: Employment status, mental disorders and service use in the working age population. Scand J Work Environ Health 2007, 33:29-36.

31. Lindström $K$, Hottinen $V$, Kivimäki M: Healthy organization questionnaire. Structure and use (Terve organisaatio -kysely. Menetelmän perusrakenne ja käyttö. [Finnish]). Helsinki: Finnish Institute of Occupational Health; 1997.

32. Karasek R, Brisson C, Kawakami N, Houtman I, Bongers P, Amick B: The Job Content Questionnaire (JCQ): an instrument for internationally comparative assessments of psychosocial job characteristics. J Occup Health Psychol 1998, 3:322-355.

33. Sarason I, Levine H, Basham R, Sarason B: Assessing social support: the social support questionnaire. J Pers Soc Psychol 1983, 44(1):127-139.

34. Greenglass ER, Julkunen J: Construct validity and sex differences in CookMedley hostility. Pers Indiv Differ 1989, 10(2):209-218.

35. Virtanen M, Honkonen T, Kivimäki M, Ahola K, Vahtera J, Aromaa A, Lönnqvist J: Work stress, mental health and antidepressant medication. Findings from the Health 2000 Study. J Affect Disord 2000, 2007(98):189-197.

36. Herttua K, Martikainen P, Vahtera J, Kivimaki M: Living alone an alcoholrelated mortality: a population-based cohort study from Finland. PLOS Med 2011, 8:1-11, (e1001094).

37. Clark C, Stansfeld SA, Candy B: A systematic review on the effect of the physical environment on mental health [abstract]. Epidemiology 2006, 17: S527.

38. Smith TW: Concepts and methods in the study on anger, hostility, and health. In Anger, hostility, and the heart. Edited by: Siegman AW, Smith TW. Hillsdale, New Jersey: Lawrence Erlbaum; 1994:23-42.

39. Hämäläinen J, Isometsä E, Sihvo S, Kiviruusu O, Pirkola S, Lönnqvist J: Treatment of major depressive disorder in the Finnish general population. Depress Anxiety 2008, 26(11):1049-4059.

40. Gardarsdottir H, Heerdink ER, van Dijk L, Egberts AC: Indications for antidepressant drug prescribing in general practice in the Netherlands. Affect Disord 2007, 98(1-2):109-115.

\section{Pre-publication history}

The pre-publication history for this paper can be accessed here: http://www.biomedcentral.com/1471-2458/12/236/prepub

doi:10.1186/1471-2458-12-236

Cite this article as: Pulkki-Råback et al:: Living alone and antidepressant medication use: a prospective study in a working-age population. BMC Public Health 2012 12:236.

\section{Submit your next manuscript to BioMed Central and take full advantage of:}

- Convenient online submission

- Thorough peer review

- No space constraints or color figure charges

- Immediate publication on acceptance

- Inclusion in PubMed, CAS, Scopus and Google Scholar

- Research which is freely available for redistribution

Submit your manuscript at www.biomedcentral.com/submit
C Biomed Central 